\title{
Carbon Monoxide and Soot Emissions from Liquid-Fueled Buoyant Turbulent Diffusion Flames
}

\author{
Ü. Ö. KÖYLÜ and G. M. FAETH* \\ Department of Aerospace Engineering, The University of Michigan, Ann Arbor, MI 48109-2140 USA
}

\begin{abstract}
Carbon monoxide concentrations, soot concentrations, and mixture fractions were measured in the fuel-lean (overfire) region of liquid-fueled buoyant turbulent diffusion flames burning in still air. Pool-fire configurations were studied with the liquids burning from horizontal round wicks, considering both sooting (toluene, benzene, $n$-heptane, and isopropanol) and nonsooting (methanol and ethanol) fuels. Flame heights and characteristic residence times also were measured, both for the turbulent flames and at the normal smoke point (for the sooting fuels). Carbon monoxide and soot generation factors (mass of $\mathrm{CO}$ or soot emitted per unit mass of fuel carbon burned) were uniform throughout the overfire region and were relatively independent of flame residence times (which were generally an order of magnitude longer than the normal smoke point residence times of the sooting fuels). Processes of carbon monoxide and soot emission for the nonalcohols are closely related, based on the good correlation between their emission factors: $0.37 \mathrm{~kg} \mathrm{CO} / \mathrm{per} \mathrm{kg}$ soot with a standard deviation of 0.09 . However, nonsooting methanol and ethanol/air flames still emitted low levels of $\mathrm{CO}$ so that there is a component of $\mathrm{CO}$ emissions that is not associated with soot.
\end{abstract}

\section{NOMENCLATURE}

$g \quad$ acceleration of gravity

$C_{p} \quad$ specific heat at constant pressure

$d$ burner exit diameter

$d_{p} \quad$ soot particle effective optical diameter

$f$ mixture fraction

$f_{s} \quad$ soot volume fraction

$L \quad$ flame height

$L_{s} \quad$ flame height at laminar smoke point

$\dot{m}_{f}$ fuel mass flow rate

$\dot{m}_{f s} \quad$ fuel mass flow rate at laminar smoke point

$M_{i} \quad$ molecular weight of substance $i$

$\dot{Q}_{f} \quad$ flame heat release rate

$Q^{*}$ dimensionless heat release parameter (Eq. 1)

$r \quad$ radial distance

$\mathrm{Ri}$ burner Richardson number, $g d / \boldsymbol{u}_{0}{ }^{2}$

$t_{r} \quad$ characteristic flame residence time

$t_{s} \quad$ characteristic residence times at laminar smoke point

$t^{*} \quad$ dimensionless residence time parameter (Eq. 2)

$T$ temperature

$u \quad$ streamwise velocity

$x \quad$ height above burner

\footnotetext{
* Corresponding author
}

Copyright (C) 1991 by The Combustion Institute Published by Elsevier Science Publishing Co., Inc.
$X_{i} \quad$ mole fraction of species $i$

$Y_{i} \quad$ mass fraction of species $i$

\section{Greek Symbols}

$\eta_{\mathrm{CO}} \quad$ carbon monoxide generation factor

$\eta_{\mathrm{CO} / s}$ carbon monoxide/soot generation correlation

$\eta_{s} \quad$ soot generation factor

$\lambda \quad$ wavelength of light

$\rho$ density

$\rho_{s} \quad$ density of soot

\section{Subscripts}

c flame axis

$q \quad$ conditions where soot oxidation quenches

$o$ burner exit condition

$\infty \quad$ ambient condition

\section{INTRODUCTION}

The present investigation considers the emissions of carbon monoxide and soot, as well as the correlation between these emissions, for liquidfueled buoyant turbulent diffusion flames typical of overventilated natural fires. The correlation between these emissions is important because they 
both are major contributors to hazards: inhalation of carbon monoxide is the main cause of fire fatalities, continuum radiation from soot increases fire growth and burning rates, and soot-laden smoke obscures fire fighting efforts. Many workers have noted a correlation between carbon monoxide and soot emissions, suggesting a synergism of these hazards that has important implications concerning materials properties for improved fire safety [1-6]. Earlier work in this laboratory confirmed this behavior for buoyant turbulent diffusion flames involving gaseous alkane, alkyne, and alkene fuels burning in still air $[7,8]$. The present study extends this work to a broader range of hydrocarbons, including aromatics and alcohols, by considering liquid fuels in pool-like flame configurations.

The discussion of past work is brief because carbon monoxide and soot emissions from buoyant turbulent diffusion flames recently were reviewed by Köylü et al. [8]. Buoyant turbulent diffusion flames generally have modest stretch rates so that concentrations of major gas species satisfy the laminar flamelet concept [9], where concentrations of major gas species are correlated solely as a function of mixture fraction (or fuelequivalent ratio) called state relationships. Measurements in laminar flames have provided state relationships for a number of fuels burning in air, including soot-containing flames, which have been applied with some success to estimate scalar properties in turbulent flames; see Ref. 10 and citations therein. Although these generalized correlations show large concentrations of $\mathrm{CO}$ for fuel-rich conditions, they generally exhibit low concentrations of $\mathrm{CO}$ for fuel-lean conditions which contradicts observations of $\mathrm{CO}$ emissions from turbulent flames [1-5, 8]. This behavior has been explained by the limited sensitivity of $\mathrm{CO}$ measurements used to find state relationships and the possibility that $\mathrm{CO}$ being emitted from flames largely accompanies soot within the soot layer as it passes from fuel-rich to fuel-lean conditions-a region that generally is not considered when state relationships are measured due to problems of soot clogging sampling systems [8]. Recent measurements within laminar flames tend to support the latter explanation, showing levels of $\mathrm{CO}$ higher than estimates from state relationships within fuel-lean portions of the soot layer [6].
Earlier work in this laboratory examined both $\mathrm{CO}$ and soot emissions from gas-fueled (acetylene, propylene, ethylene, propane, and methane) buoyant turbulent diffusion flames burning in still air [7, 8]. Emissions were represented by generation factors, $\eta_{\mathrm{CO}}$ and $\eta_{s}$, defined as the mass of $\mathrm{CO}$ or soot emitted per unit mass of fuel carbon burned. (This differs from $\mathrm{CO}$ or soot yields defined in Refs. 2 and 3, which are the mass of $\mathrm{CO}$ or soot emitted per unit mass of fuel burned.) It was found that $\mathrm{CO}$ and soot generation factors were relatively independent of position in the overfire region, that they tended to increase with increasing flame residence time, that they eventually reached relatively constant asymptotic values at residence times roughly an order of magnitude longer that the laminar smoke point residence time, and that emissions of $\mathrm{CO}$ and soot were strongly correlated (except for methane, which was nonsooting), yielding $\eta_{\mathrm{CO}}=$ $0.34 \eta_{s}$. This established a strong correlation between mechanisms producing $\mathrm{CO}$ and soot in these flames, supplemented by a weaker mechanism not involving soot to explain measurable but low levels of $\mathrm{CO}$ emissions from nonsooting methane flames.

The objective of the present investigation was to determine whether the trends concerning $\mathrm{CO}$ and soot emissions from gas-fueled buoyant turbulent diffusion flames $[7,8]$ extended to a broader class of hydrocarbons accessible as liquid fuels. Fuels considered included aromatics (toluene and benzene), a heavy saturated hydrocarbon ( $n$-heptane) and three alcohols (isopropanol, ethanol, and methanol). Ethanol and methanol were of interest to highlight the nonsooting $\mathrm{CO}$ emission mechanism because flames with these fuels did not emit soot for present test conditions. Measurements included the following properties for the turbulent flames: soot and $\mathrm{CO}$ concentrations in the overfire region, soot and $\mathrm{CO}$ emission factors and their correlation, flame lengths, and flame residence times. Measurements also were made of laminar smoke point flame lengths and residence times. The measurements of $\mathrm{CO}$ and soot properties were needed for the direct objectives of the study, while measurements of flame lengths and residence times help characterize present test conditions and their relationship to the long residence time regime. 


\section{EXPERIMENTAL METHODS}

\section{Turbulent Flame Apparatus}

The overall test arrangement was similar to the earlier gas-fueled experiments [7, 8], aside from different burner systems to accommodate liquid fuels. The present experiments involved burning from round, horizontal, fuel-soaked wicks that were facing upward. Combustion was in still air with the wicks located near the axis of a large enclosure $(2.4 \times 2.4 \times 3.6 \mathrm{~m}$ high $)$. The enclosure had a metal hood at the top and an adjustable exhaust system to collect and remove combustion products without disturbing the flames. Room disturbances of the flames were minimized by using strips of plastic film, terminating near the floor, as the side walls of the enclosure, and a second smaller screened enclosure $(1 \times 1 \times 2 \mathrm{~m}$ high, open at the top) directly around the flames. Instrumentation was mounted rigidly so that the burner was traversed horizontally and vertically (with positioning accuracies of 0.1 and $1 \mathrm{~mm}$, respectively) to make measurements at various points within the fuel-lean (overfire) region of the flames.

Figure 1 is a sketch of the burner assembly. Fuel was supplied to the flames from round fuelsaturated wicks (Carborundum Co., Duraboard KBLD162436, $25 \mathrm{~mm}$ thick). The wicks were mounted level with the top of close-fitting stainless-steel pans so that burning from the sides of the wicks was inhibited. Three burner (wick) diameters were considered: 50, 125, and 195 $\mathrm{mm}$. This allowed evaluation of effects of scale while maintaining turbulent flames of reasonable size so that properties could be measured in the cool portions of the plume.

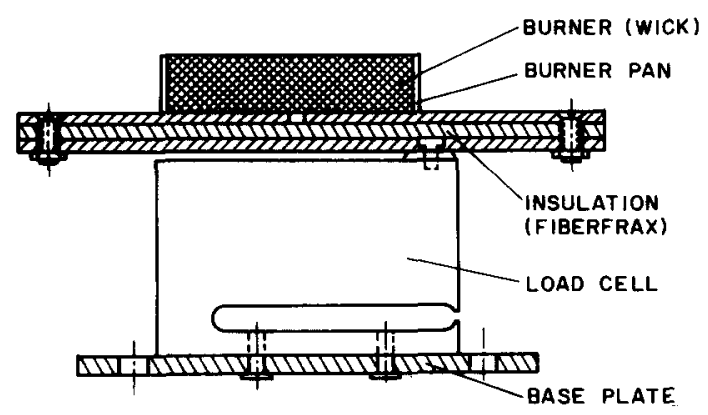

Fig. 1. Sketch of the burner assembly.
Heat soak-back to the wick assembly caused gradual increases of the burning rate with time. Therefore, burning rates were monitored so that they could be known in the period when measurements were made. This was done by mounting the wick burner pans on a load cell (Interface, Model SPI-15, single-point type, $6.8 \mathrm{~kg}$ capacity). Thermal disturbances of the load cell were controlled by an insulated barrier at the bottom of the burner pan. The output of the load cell was amplified and then stored and processed with a microcomputer. The arrangement was calibrated using weights of known mass. Experimental uncertainties ( $95 \%$ confidence) of the burning rate measurements for the turbulent flames were less than $5 \%$.

\section{Laminar Smoke Point Apparatus}

Laminar smoke point properties of the liquidfueled flames were measured to establish long residence time conditions for the present flames. This involved use of the same wick system as the turbulent flame tests but with much smaller wick diameters: 5-25 $\mathrm{mm}$ in increments of $5 \mathrm{~mm}$ with wick thicknesses of $25 \mathrm{~mm}$. These tests also involved burning in still air within a screened enclosure to control room disturbances.

The small-diameter wicks exhibited progressively decreasing burning rates and flame heights with time. Thus, the procedure to find laminar smoke points involved selecting a wick diameter where the flame emitted soot at first but eventually reached the smoke point as the flame became shorter. The laminar smoke point was defined in the same manner as Schug et al. [11], as the point where the tips of the small luminous protuberance from the soot layer (the " wings") coincided with the tip of the flame.

The flame height at the laminar smoke point was measured from flame photographs, as is described later. Flame height determinations largely were limited by exactly specifying protuberance and flame heights and disturbances of the longer flames. In view of these factors, experimental uncertainties ( $95 \%$ confidence) of laminar smoke point flame heights are estimated to be less than $10 \%$.

The effect of burner diameter on the laminar smoke point flame height also was examined. For 
the range of diameters that could be considered for a particular fuel using present methods (generally less than $2: 1$ ), the burner diameter did not affect the smoke point flame height within experimental uncertainties.

\section{Instrumentation}

\section{Flame Photography}

In addition to monitoring the burning rate, the turbulent flames were characterized by measuring their flame heights and characteristic residence times similar to Ref. 7. Except for methanol, the test flames were luminous and were readily photographed in a darkened room for these determinations. This involved motion picture photographs (200-1000 pps using 16-mm Kodak 4X film) with $100-$ and $1000-\mathrm{Hz}$ timing marks on the film, depending on conditions.

Flame height measurements were obtained by averaging luminous flame heights (taken as the highest position where luminosity was observed) on 100 pictures, obtained over a 5-10-s period. The experimental uncertainties (95\% confidence) of the flame heights are estimated to be less than $10 \%$.

Characteristic flame residence times (called "residence times"' in the following) were defined in the same manner as in Ref. 7, as the time interval between interruption of the fuel flow and the disappearance of all flame luminosity. These measurements were made for both the turbulent flames and at the laminar smoke points. The fuel flow rate was terminated by a pneumatically driven shutter passing across the burner a few millimeters above its surface. Shutter speeds allowed the leading edge of the shutter to cross the burner exit in less than 2-40 ms for the 5-195mm-diameter burners. Camera speeds yielded less than 2 and $10 \mathrm{~ms}$ discretization errors on the films for the laminar and turbulent flames. Ten tests were averaged to find the characteristic residence time for each flame condition to yield experimental uncertainties (95\% confidence) estimated to be less than $20 \%$ for the laminar flames and $10 \%$ for the turbulent flames.

\section{Optical/Sampling Probe}

Mean soot volume fractions and mixture fractions were measured simultaneously using the optical/sampling probe described in Ref. 7. These measurements were limited to the far overfire region (mean fuel-equivalence ratios less than $4 \times 10^{-3}$ and mean temperatures less than 450 $\mathrm{K}$ ), where relationships between mean and instantaneous scalar properties are the same. The system involves drawing a sample into a $25 \times 25$ $\mathrm{mm}$ passage where mean soot volume fractions are measured by laser extinction, and mean mixture fractions are measured by gas chromatography. Sampling was not isokinetic (velocities were unknown); however, effects of doubling and halving sampling rates were negligible.

The 632.8-nm line of a HeNe laser was used for the extinction measurements, with the beam making 16-18 passes across the sample to achieve extinction levels needed for acceptable experimental uncertainties. The extinction ratio was obtained by averaging ten groups of 5000 samples, each obtained over a 10 -s period.

Past multiline laser extinction measurements within the fuel-rich (underfire) region of acetylene and ethylene flames suggest that effective optical size parameters of soot particles, $\pi d_{p} / \lambda$, are less than 0.5 at a wavelength of $632.8 \mathrm{~nm}$ $[12,13]$, so that discrepancies between Rayleigh and Mie scattering predictions of soot volume fractions are less that $15 \%$ [14]. Thus, to provide a common basis of comparison with earlier work $[2,3,6,7]$, soot volume fractions were inferred from the laser extinction measurements assuming Rayleigh scattering and using the soot refractive index measurements of Dalzell and Sarofim [15], i.e., $1.547-0.56 i$ at $632.8 \mathrm{~nm}$. Due to the simplicity of the Rayleigh scattering relationship between soot volume fraction and laser extinction [14], this approach also has the advantage that present results can be readily corrected if new information about the scattering properties of overfire soot for the present fuels becomes available.

Aside from uncertainties about the Rayleigh scattering approximation and the appropriate refractive indices of soot, experimental uncertainties of soot volume fractions were largely controlled by the magnitude of the laser extinction ratio and finite sampling times: they are estimated ( $95 \%$ confidence) to be less than $30 \%$ for soot volume fractions greater than $2 \times 10^{-3} \mathrm{ppm}$, which was the lowest value considered during the tests. 
Samples for gas composition and mixture fraction measurements were filtered to remove water vapor so that analysis was on a dry basis. The arrangement and operating conditions of the gas chromatograph, and methods of data reduction, were the same as Gore [16]. Experimental uncertainties (95\% confidence) are estimated to be less than $10 \%$ for the concentrations of major gas species and less than $20 \%$ for mixture fractions.

\section{Gas Sampling Probe}

Carbon monoxide concentrations and mixture fractions were measured simultaneously using the same arrangement as Ref. 8. The approach is described completely herein because few details are provided in Ref. 8 . The $\mathrm{CO}$ measurements were made in the far overfire region at the same locations as the soot volume fraction measurements. Sampling involved an uncooled 5-mm-diameter probe because the low temperatures (less than $450 \mathrm{~K}$ ) assured a passive environment. No attempt was made to sample isokinetically because only relationships between $\mathrm{CO}$ concentrations and mixture fractions were sought.

An NDIR analyzer (Beckman, Model 867) was used for the $\mathrm{CO}$ measurements. The sample was dried and filtered before entering the analyzer to reduce uncertainties from the presence of water vapor and particulates. The sampling train included the following components: a coil condenser constructed of 5-mm-diameter tubing, $1500 \mathrm{~mm}$ long, within an ice bath; a trap and in-line filter to remove condensate and particles having sizes greater than $5 \mu \mathrm{m}$; a HEPA capsule filter (Gelman 12144) having a diameter of 59 $\mathrm{mm}$ and a length of $185 \mathrm{~mm}$ to remove particles larger than $0.3 \mu \mathrm{m}$ with $99.96 \%$ efficiency; a drying unit (Nalgene 6201-0080) $200 \mathrm{~mm}$ long containing $20 \mathrm{~g}$ calcium chloride; a Drierite indicating drying tube (Grainger 17838) to serve as a second drying column; a diaphragm pump; a rotameter to monitor sample flow rates; and finally the NDIR analyzer. Flow rates through the sampling train were in the range $50-60 \mathrm{ml} / \mathrm{s}$ to provide proper instrument operation and reasonable purging times.

Present $\mathrm{CO}$ concentrations were in the range 1-200 ppm and were found using the lowest three ranges of the NDIR analyzer (0-50, $0-200$ and $0-1000 \mathrm{ppm})$. The analyzer was calibrated before and after testing each day using prepared gas mixtures (Scott Specialty Gases: 10.10, 99.93, 949.3, $2299 \mathrm{ppm}$ of $\mathrm{CO}$ in air; 4.97 and $13.91 \% \mathrm{CO}_{2}$ in air). The output of the analyzer was stored and processed using a microcomputer, sampling at $250 \mathrm{~Hz}$ and averaged over $40 \mathrm{~s}$, repeating and averaging over ten such intervals to achieve day-to-day repeatability within $10 \%$. The sampling system was purged with $\mathrm{CO}$-free air between each measurement until baseline zero values were retrieved.

Experimental uncertainties of the $\mathrm{CO}$ measurements were dominated by limited sensitivity due to the overlap of the infrared gas bands of $\mathrm{CO}$ and $\mathrm{CO}_{2}$ and finite sampling times: they are estimated ( $95 \%$ confidence) to be less than $10 \%$ for concentrations greater than $10 \mathrm{ppm}$, increasing inversely with concentration for lower values. Methods of measuring mixture fractions, and the uncertainties of these measurements, were the same as for the optical/sampling probe.

\section{Test Conditions}

Test conditions are summarized in Table 1. Richardson numbers are based on burner exit conditions finding the velocity from the measured burning rate while assuming that the density of the mixture was equal to the fuel density at the normal boiling point. The Richardson numbers are generally in excess of 5000 , which is representative of strongly buoyant flames. All the flames were turbulent, except near their base. Ranges of other properties of the flames were comparable to the gas-fueled buoyant turbulent flames of Refs. 7 and 8: heat release rates of $2.3-20.5 \mathrm{~kW}$, flame lengths of $190-650 \mathrm{~mm}$, and residence times of $126-532 \mathrm{~ms}$. Flame heights and residence times could not be measured for methanol by present methods because light emission from these flames was too weak; therefore, the values in Table 1 for methanol were estimated using correlations that are discussed later. Measurements were made at various heights above the burner, $x / d$ of 3.6-35.0, both at the axis and at $r / x$ of 0.06 and 0.012 so that flows leaving various points along the flame sheet could be studied.

Present measurements of laminar smoke point properties of the fuels are summarized in Table 2 . The burning rates for these tests were too small to be measured using present methods; therefore, 
TABLE 1

Summary of Test Conditions ${ }^{a}$

\begin{tabular}{|c|c|c|c|c|c|c|}
\hline $\begin{array}{c}d \\
(\mathrm{~mm})\end{array}$ & $\mathrm{Ri}^{b}$ & $\begin{array}{c}\dot{m}_{f} \\
(\mathrm{mg} / \mathrm{s})\end{array}$ & $\underset{(\mathrm{kW})}{\dot{Q}_{f}}$ & $\begin{array}{c}L \\
(\mathrm{~mm})\end{array}$ & $\begin{array}{c}t_{t}^{c} \\
(\mathrm{~ms})\end{array}$ & $x / d^{d}$ \\
\hline \multicolumn{7}{|c|}{ Toluene $\left(\rho_{0}=3.11 \mathrm{~kg} / \mathrm{m}^{3}\right)$} \\
\hline 50 & 6270 & 54 & 2.3 & 295 & 279 & $14.2-35.0$ \\
\hline 125 & 15450 & 340 & 14.4 & 520 & 531 & $7.6-16.7$ \\
\hline \multicolumn{7}{|c|}{ Benzene $\left(\rho_{0}=2.69 \mathrm{~kg} / \mathrm{m}^{3}\right)$} \\
\hline 50 & 3150 & 66 & 2.7 & 280 & 273 & $14.2-35.0$ \\
\hline 125 & 10930 & 350 & 14.1 & 525 & 510 & $7.6-16.7$ \\
\hline \multicolumn{7}{|c|}{$n$-Heptane $\left(\rho_{0}=3.29 \mathrm{~kg} / \mathrm{m}^{3}\right)$} \\
\hline 50 & 11040 & 43 & 1.9 & 275 & 212 & $10.8-19.0$ \\
\hline 125 & 58230 & 185 & 8.2 & 450 & 412 & $6.5-11.5$ \\
\hline 195 & 87010 & 460 & 20.5 & 650 & 532 & $7.4-9.4$ \\
\hline \multicolumn{7}{|c|}{ Isopropanol $\left(\rho_{0}=2.06 \mathrm{~kg} / \mathrm{m}^{3}\right)$} \\
\hline 50 & 5860 & 37 & 1.2 & 190 & 126 & $10.8-14.2$ \\
\hline 125 & 30610 & 160 & 5.3 & 370 & 324 & $5.6-6.5$ \\
\hline 195 & 47600 & 390 & 12.9 & 510 & 495 & $7.4-8.3$ \\
\hline \multicolumn{7}{|c|}{ Ethanol $\left(\rho_{0}=1.60 \mathrm{~kg} / \mathrm{m}^{3}\right)$} \\
\hline 125 & 19350 & 156 & 4.2 & 290 & 245 & $5.6-7.6$ \\
\hline 195 & 36140 & 347 & 9.3 & 395 & 412 & $3.6-4.9$ \\
\hline \multicolumn{7}{|c|}{ Methanol $\left(\rho_{0}=1.15 \mathrm{~kg} / \mathrm{m}^{3}\right)$} \\
\hline 125 & 10320 & 155 & 3.1 & $260^{e}$ & $224^{f}$ & $4.5-6.5$ \\
\hline 195 & 19130 & 345 & 6.8 & $330^{e}$ & $335^{f}$ & $3.6-4.9$ \\
\hline
\end{tabular}

${ }^{a}$ Combustion from a round horizontal wick in still air at normal temperature and pressure.

${ }^{b} \mathrm{Ri}=g d / u_{0}^{2}$ using the fuel vapor density at normal boiling point to estimate $u_{0}$.

${ }^{c}$ Time between termination of fuel flow and disappearance of all flame luminosity.

${ }^{d}$ Measurements at $r / x=0.00,0.06$ and 0.12 for this range of $x / d$.

${ }^{e}$ Calculated from correlation of Zukoski et al. [17], Eq. 2.

${ }^{f}$ Calculated from present residence time correlation, Eq. 5 .

only qualitative values are given in the table for reference purposes, computed following Zukoski et al. [17] from the present flame length measurements. Laminar smoke point flame heights and residence times, however, were measured as de-

\section{TABLE 2}

Laminar Smoke Point Properties ${ }^{a}$

\begin{tabular}{llllc}
\hline \multicolumn{1}{c}{ Fuel } & \multicolumn{5}{c}{ Toluene } & Benzene & $n$-Heptane & Isopropanol \\
\hline Present Study: & & & & \\
$d(\mathrm{~mm})$ & 5 & 5 & 20 & 25 \\
$\dot{m}_{f s}(\mathrm{mg} / \mathrm{s})^{b}$ & 0.05 & 0.06 & 4.6 & 8.0 \\
$\dot{Q}_{f}(\mathrm{~W})^{b}$ & 2.1 & 2.4 & 205 & 264 \\
$L_{s}(\mathrm{~mm})$ & 17 & 18 & 106 & 118 \\
$t_{s}(\mathrm{~ms})$ & 13 & 15 & 41 & 49 \\
Olson et al. $[18]:$ & & & & \\
$\dot{m}_{f s}(\mathrm{mg} / \mathrm{s})$ & 0.27 & - & 5.13 & - \\
$L_{s}(\mathrm{~mm})$ & 7 & - & 125 & - \\
Clark et al. $[19]$ & & & & \\
$L_{s}(\mathrm{~mm})$ & 10 & 9 & 159 & 179 \\
\hline
\end{tabular}

${ }^{a}$ Combustion of liquid fuel in air at normal temperature and pressure.

${ }^{b}$ Calculated from correlation of Zukowski et al. [17], Eq. 2. scribed earlier. Laminar smoke point flame lengths for burning in an air coflow, from Olson et al. [18], found using a cylindrical fuel-saturated wick, and Clarke et al. [19], found by increasing the liquid pool diameter in a funnel-shaped fuel reservoir, also are summarized in Table 2. Due to the different test methods, values of $L_{s}$ from the three studies only agree qualitatively, e.g., variations of preheating for different wick designs and various levels of coflow cause variations of $L_{s}$ [11].

In spite of quantitative differences among the three determinations of $L_{s}$ listed in Table 2, there is general agreement about the order of the propensity to soot: toluene and benzene about the same with $n$-heptane and isopropanol having progressively weaker tendencies to soot. In addition, methanol and ethanol did not emit soot for any laminar flame condition using present test methods. Furthermore, none of the turbulent methanol and ethanol flames emitted any soot, based on extensive measurements with the optical/sampling probe as well as thermophoretic sampling 
for long time periods and observations using TEM.

Laminar smoke point residence times in Table 2 increase in the same order as $L_{s}$. For the sooting fuels, the turbulent flames have $t_{r} / t_{s}$ in the range 2.6-41, which corresponds to the long residence time regime where emissions of soot and $\mathrm{CO}$ were relatively independent of flame residence time for the gaseous fuels $[7,8]$.

\section{RESULTS AND DISCUSSION}

\section{Flame Heights}

Flame heights and residence times will be considered first in order to help characterize the test conditions. Flame heights for the three burners and all the fuels except methanol (where the flame heights could not be observed, as noted earlier) are illustrated in Fig. 2. The results are plotted according to the scaling relationships of
Zukoski et al. [17] for buoyant flames. This involves plotting $L / d$ as a function of the dimensionless heat release parameter.

$Q^{*}=\dot{Q}_{f} /\left(\rho_{\infty} C_{p \infty} T_{\infty} g^{1 / 2} d^{5 / 2}\right)$

Measurements for the gas-fueled buoyant turbulent diffusion flames, studied earlier [7], along with several other sets of measurements for a variety of gas, liquid, and solid fuels [17, 20-22], are also shown on the plot.

The present flame height measurements in Fig. 2 are in excellent agreement with those of Sivathanu and Faeth [7] and Zukoski et al. [17], which involved different burners but similar measuring techniques. The flame length determinations of Refs. 20-22 are somewhat longer probably because they are based on direct visual observations. However, the differences among all the measurements are not large in view of the subjective nature of the fluctuating visible length

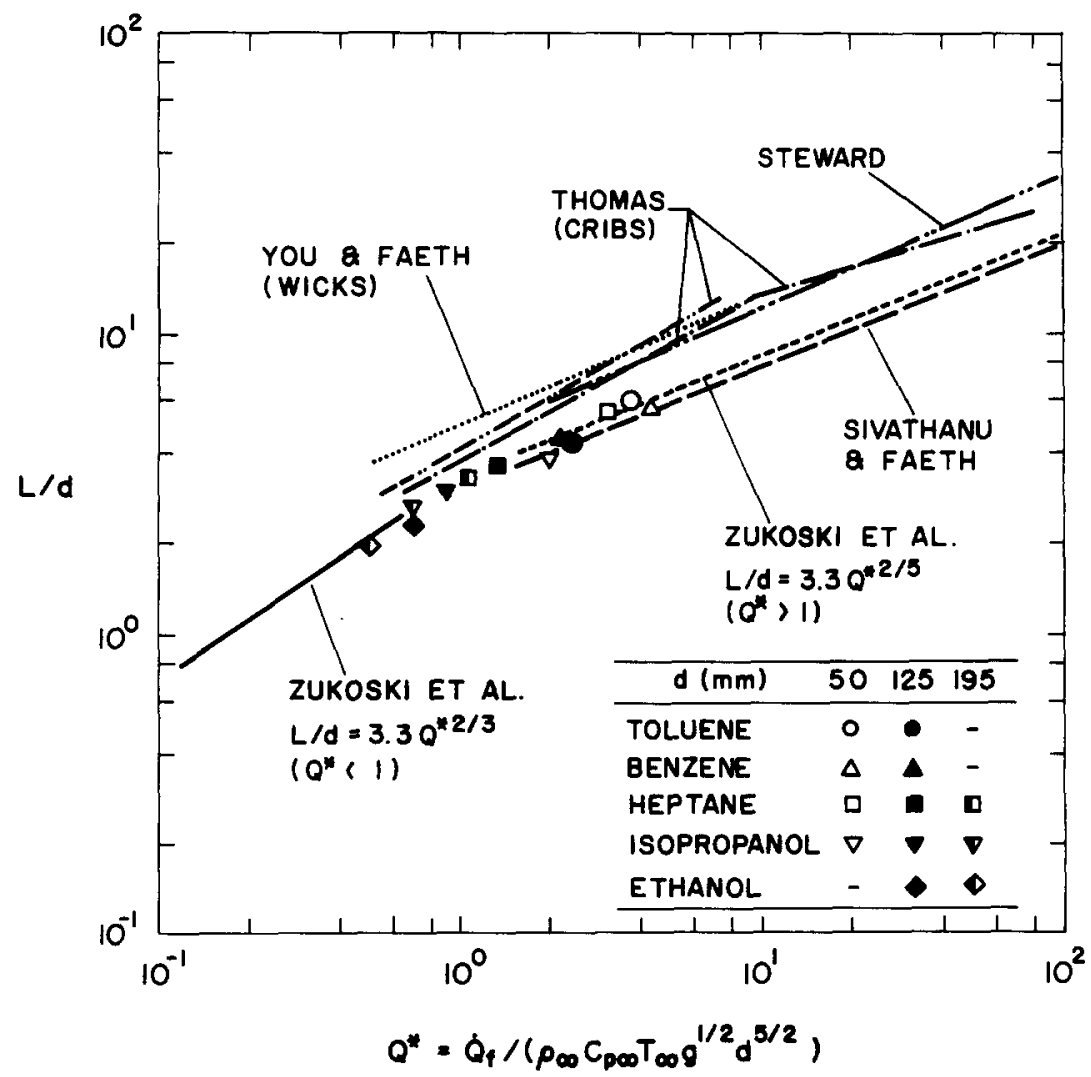

Fig. 2. Flame heights as a function of heat release rate for buoyant turbulent diffusion flames. Other data from Sivathanu and Faeth [7], Zukoski et al. [17], Steward [22], Thomas [21], and You and Faeth [22]. 
of a turbulent diffusion flame. Thus, the present flames are typical of buoyant pool fires and their lengths are reasonably correlated by the expression proposed by Zukoski et al. [17]:

$$
\begin{array}{ll}
L / d=3.3 Q^{* 2 / 3}, & Q^{*}<1 ; \\
L / d=3.3 Q^{* 2 / 5}, & Q^{*} \geq 1 .
\end{array}
$$

Due to the reasonable agreement between present measurements and Eq. 2, it was used to estimate $L$ for the turbulent methanol flames in Table 1, and $\dot{Q}_{f s}$ and $\dot{m}_{f s}$ from the measured value $L_{s}$ at the laminar smoke points in Table 2.

\section{Residence Times}

Flame residence times are important in order to estimate approach to the long residence time regime. A correlation of this property was developed in Ref. 7; however, this approach was not effective for present measurements and it was revised. The present procedure was to associate the characteristic flame residence time with the time required for a fluid parcel to pass from the burner exit to the mean tip of the flame, as follows:

$t_{r} \sim \int_{0}^{L} u_{c}^{-1} d x$

Drysdale [23] indicates that velocities along the axis of buoyant turbulent flames can be correlated as follows:

$$
u_{\mathrm{c}} \sim\left(g \dot{Q}_{f} / \rho_{\infty} C_{p \infty} T_{\infty} x\right)^{1 / 3} \text {. }
$$

Substituting Eq. 4 into Eq. 3 and completing the integration yields an expression for the residence time in terms of the flame length. Eliminating the flame length from this expression, using the correlations of Eq. 2, and selecting the constant of proportionality resulting from Eqs. 3 and 4 to best match the present data and that of Ref. 7, yields the following residence time correlations:

$$
\begin{array}{ll}
t^{*}=2.9 Q^{* 5 / 9}, & Q^{*}<1 ; \\
t^{*}=2.9 Q^{* 1 / 5}, & Q^{*} \geq 1,
\end{array}
$$

where

$t^{*}=t_{r}(g / d)^{1 / 2}$.
Values of $t^{*}$ are plotted as a function of $Q^{*}$ in Fig. 3. Measurements are shown for the present liquid-fueled flames and for the buoyant gasfueled flames of Ref. 7, along with the correlations of Eq. 5. The correlations yield the trends of the data reasonably well and quantitative agreement is within experimental uncertainties except for the results for acetylene. The values of $t^{*}$ for acetylene generally are $20 \%$ lower than the rest but the reasons for this behavior are not known; notably, the approach of Ref. 7 provides a better correlation of the acetylene results. Nevertheless, the correlations of Eq. 5 provide a convenient estimate of residence times that is consistent with the flame length correlations of Zukoski et al. [17] (Eq. 2). These expressions were used to estimate $t_{r}$ for the methanol flames in Table 1 because weak flame luminosity prevented direct measurement of $t_{r}$ by present methods, as noted earlier.

Equation 5 provides some insight about the scaling of present residence times to practical fires. For larger flames, $Q^{*}>1$ and the residence time is proportional to $\dot{Q}_{f}^{1 / 5}$ and is independent of $d$. Thus, residence times only increase by roughly a factor of 2 when burning rates are increased from the larger flames of Table 1 to the MW range of practical fires.

\section{Soot Properties}

The present optical/sampling probe measurements were limited to the far overfire region where differences between time-averages and mass-weighted (Favre) averages are small, and where relationships between time-averaged and instantaneous scalar properties are identical. Furthermore, soot oxidation in the fuel-lean region quenches near the luminous flame [24] so that soot behaves like a passive scalar in the overfire region. Then variations of soot volume fractions only are caused by variations of soot concentrations at the point where soot oxidation reactions quench and the extent of mixing with the surrounding air.

Under these circumstances, adopting the usual approximations of the conserved-scalar formalism, and assuming that properties when soot reactions quench are independent of position in the flame, yields a simple expression (or state relationship) for soot concentrations in the overfire 
region. In particular, effects of preferential diffusion, kinetic energy, and radiative heat loss are ignored; soot concentrations are represented by their volume fractions; and the volume occupied by soot is neglected when computing mixture density. These are reasonable assumptions for the overfire region of the present flames. Reynolds numbers are relatively high so that turbulent mixing dominates and the low molecular diffusivity of soot has little effect. Additionally, temperatures are moderate and velocities are relatively high over most of the overfire region so that radiation numbers are small. Finally, soot volume fractions are generally less than $1 \mathrm{ppm}$ so that the volume of soot can be neglected when finding the mixture density with little error. Then, the state relationship for soot volume fraction is as follows:

$f_{s}=\rho f\left(f_{s} / \rho f\right)_{q}$,

where the subscript $q$ denotes conditions where soot oxidation quenches. Under the approxima- tions of the conserved scalar formalism, $\rho$ only is a function of $f$ so that $f_{s}$ only is a function of $f$ for given quenching conditions as well.

Motivated by Eq. 7, the present measurements of soot volume fractions are plotted as a function of mixture fraction in Fig. 4. Results are only shown for the sooting fuels: toluene, benzene, $n$-heptane, and isopropanol. As noted earlier, no soot was detected in the overfire region of the present methanol and ethanol flames. To avoid cluttering the figure, symbols only are identified by the fuel and the burner size: the measurements also involved a range of positions in the overfire region as noted in Table 1 . Finally, toluene and benzene emitted large quantities of soot and had high flame radiation levels due to continuum radiation from soot; therefore, it was difficult to make measurements with these flames for the largest burner and only the two smaller burners were used. All three burners, however, were used for the more lightly sooting $n$-heptane and isopropanol flames.

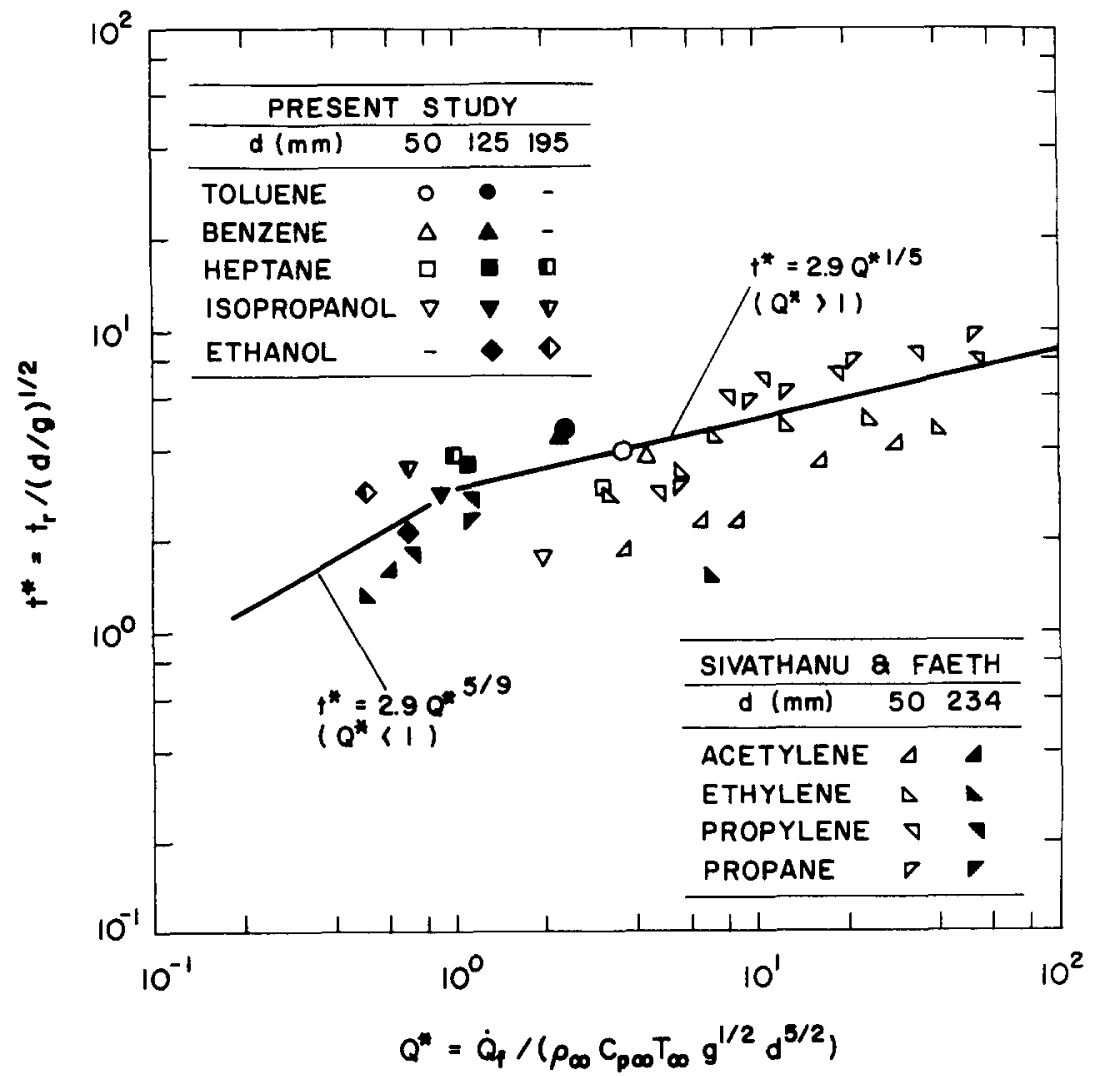

Fig. 3. Characteristic flame residence times as a function of heat release rate for buoyant turbulent diffusion flames. Other data from Sivathanu and Faeth [7]. 
The soot volume fraction measurements illustrated in Fig. 4 for each fuel generally fall along correlations of the best fits of the data constructed according to $\mathrm{Eq}$. 7. The correlations are nearly straight lines in Fig. 4 because present test conditions involve relatively low mixture fractions, less than $4 \times 10^{-3}$, where variations of density with $f$ in Eq. 7 are small. Noting that results for a particular symbol involve various positions in the overfire region for particular flames, it is evident that these results correlate quite well assuming passive mixing and constant conditions when soot oxidation quenches at various points within the flame. Except for isopropanol, there is a tendency for soot volume fractions to increase

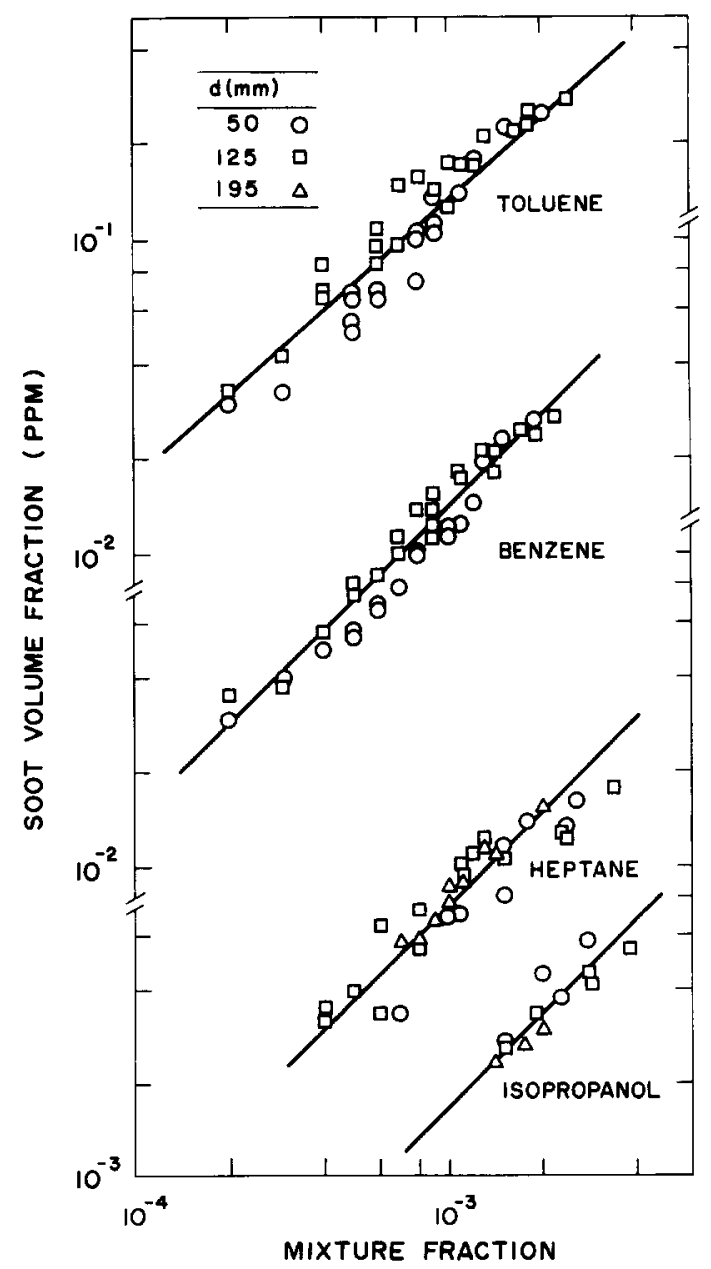

Fig. 4. Soot volume fraction state relationships for the overfire region of turbulent toluene, benzene, $n$-heptane, and isopropanol diffusion flames burning in air. Note that nheptane and isopropanol are on the same cut of the plot. slightly with increasing burner size (this is most evident for toluene and benzene). Although this trend is consistent, the effect is not large in comparison to present experimental uncertainties. The results illustrated in Fig. 4 also correlate quite well with sooting tendencies based on laminar smoke point flame lengths: at a given value of $f, f_{s}$ for toluene and benzene are comparable with progressively decreasing $f_{s}$ for $n$-heptane and isopropanol.

The results illustrated in Fig. 4 suggest that soot properties when soot oxidation quenches are relatively independent of position within a given flame, and that subsequent variations of $f_{s}$ are due to passive turbulent mixing within the overfire region of a given flame as represented by Eq. 7. Then, the emission of soot from a given flame can be represented conveniently by the soot generation factor, $\eta_{s}$. Analogous to the evaluation of $f, \eta_{s}$ was found by assuming that $\mathrm{H} / \mathrm{C}$ ratios were the same as the original fuel in the regions where measurements were made. Then noting that $\mathrm{CO}$ and soot concentrations are small in comparison to $\mathrm{CO}_{2}$ concentrations in the faroverfire region, $\eta_{s}$ can be found from the measured values of $f_{s}$ and $Y_{\mathrm{CO}_{2}}$ as follows:

$\eta_{s}=M_{\mathrm{CO}_{2}} \rho_{s} f_{s} /\left(M_{\mathrm{C}} \rho Y_{\mathrm{CO}_{2}}\right)$.

For consistency with past work $[7,8]$, a constant soot density of $1100 \mathrm{~kg} / \mathrm{m}^{3}$ from Newman and Steciak [25] was used for these computations: given an alternative value of $\rho_{s}$, corrections of present results are easily made as a simple ratio. The mixture density in Eq. 8 depends on the mixture fraction, which is known for each test condition, and the degree of heat loss from the present flames. Radiative heat loss fractions of the gas-fueled buoyant turbulent diffusion flames varied with the fuel but not the flame operating condition [7], typical of buoyant flames [26]; therefore, the present flames were assumed to behave in the same manner. Additionally, the radiative heat loss fractions for the present flames were estimated, using present measurements of laminar smoke point flame lengths, from the correlation of Markstein [26]. This yielded radiative heat loss fractions of $40 \%$ for toluene and benzene, and $30 \%$ for $n$-heptane and isopropanol. Fortunately, due to the low values of $f$ for present measurements, values of $\rho$ are relatively independent of heat loss fraction so that these 
approximations are not very critical (see Ref. 7 for comparison of results considering and ignoring radiative heat losses).

As anticipated from the results illustrated in Fig. 4, soot generation factors were relatively independent of position for a given flame. Thus, average soot generation factors were computed for each flame and associated with its residence time. Plots of the resulting soot generation factors, as a function of residence time normalized by the smoke point residence time, are illustrated in Fig. 5.

Variations of soot generation factors with residence time in Fig. 5 are all comparable to behavior observed in the long residence time regime for the gas-fueled turbulent diffusion flames [7], i.e., soot generation factors are relatively independent of residence time. This is reasonable, because present flames had residence times that were generally an order of magnitude longer than the smoke point residence time, which was the criterion for the long residence time regime found earlier [7]. The results exhibit relative soot emissions quite concisely, with the greatest soot emitters being toluene and benzene, which are about the same, followed in decreasing order by $n$ -

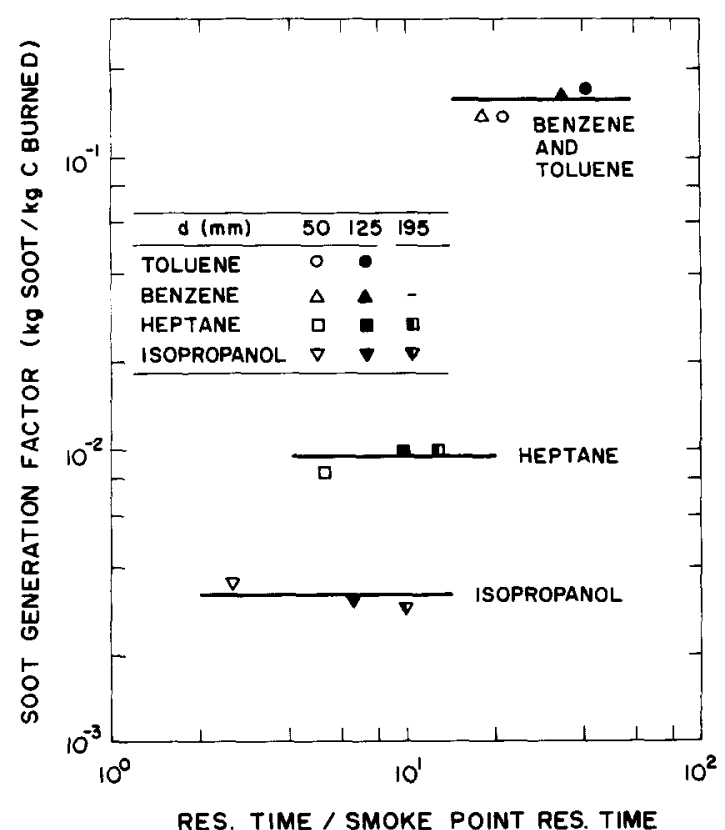

Fig. 5. Soot generation factor as a function of residence time for turbulent toluene, benzene, $n$-heptane, and isopropanol diffusion flames burning in air. heptane and isopropanol. The soot generation factors for toluene and benzene are roughly 0.15 , which is somewhat below the value for acetylene, 0.20 , measured earlier [7]. The present value of $\eta_{s}$ for the liquid alkane $n$-heptane is roughly 0.01 , which is essentially the same as the value measured earlier for the gaseous alkane, propane, in the long residence time regime [7], as corrected in Ref. 8. The comparison between the present $\eta_{s}$ and those found from the soot yields summarized by Tewarson [2] is considered later.

\section{Carbon Monoxide Properties}

The gas sampling probe measurements for $\mathrm{CO}$ properties were carried out at the same positions as the soot measurements. Proceeding under the assumptions used to find the soot volume fraction state relationships, state relationships also can be constructed for $\mathrm{CO}$ concentrations [8]. The resulting measurements and best fit correlations of $\mathrm{CO}$ mole fractions as a function of mixture fractions are illustrated in Fig. 6 for toluene, benzene and $n$-heptane, and in Fig. 7 for the alcohols. As before, measurements are only identified by the fuel and the burner diameter to avoid cluttering the figures. Due to the low mixture fraction range of the measurements, the $\mathrm{CO}$ state relationship correlations are nearly straight lines, similar to the state relationships for $f_{s}$ illustrated in Fig. 4 .

The carbon monoxide mole fractions plotted in Figs. 6 and 7 exhibit about the same degree of scatter as flame conditions change for a given value of $f$ as $f_{s}$ in Fig. 4. Additionally, the main trends of the results for $X_{\mathrm{CO}}$ and $f_{s}$ are the same. First of all, results at various positions in the overfire region of any given flame satisfy a linear correlation within experimental uncertainties. Next, results for different burner sizes satisfy nearly the same state relationship, typical of the long-residence time regime of the present flames. Finally, concentrations of $\mathrm{CO}$ at particular values of $f$ progressively decrease with decreasing tendency to soot in the order: toluene and benzene (about the same), $n$-heptane, and isopropanol (also about the same), with nonsooting ethanol and methanol having the lowest concentrations of $\mathrm{CO}$.

The effect of flame residence time and the relative propensity to soot on the emission of $\mathrm{CO}$ can be examined most concisely by computing 


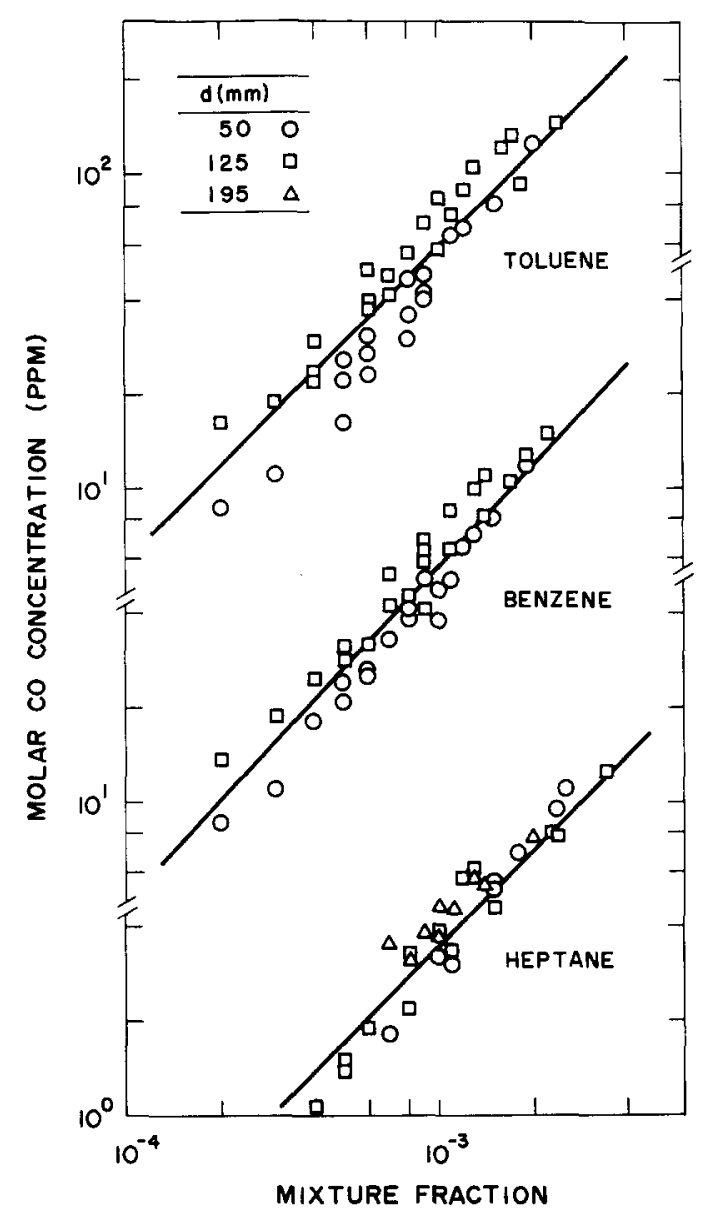

Fig. 6. Carbon monoxide state relationships for the overfire region of turbulent toluene, benzene and $n$-heptane diffusion flames burning in air.

CO generation factors, $\eta_{\mathrm{CO}}$. Similar to $\eta_{s}, \eta_{\mathrm{CO}}$ should be constant for passive mixing and constant quenching conditions for any flame. Under the same assumptions used to find $\eta_{s}, \eta_{\mathrm{CO}}$ can be found from the measured $\mathrm{CO}$ and $\mathrm{CO}_{2}$ concentrations, as follows [8]:

$\eta_{\mathrm{CO}}=M_{\mathrm{CO}} X_{\mathrm{Co}} /\left(M_{\mathrm{C}} X_{\mathrm{CO}_{2}}\right)$.

As noted earlier, $\eta_{\mathrm{CO}}$ values were relatively independent of position in a flame. Thus, an average value of $\eta_{\mathrm{CO}}$ was found for each flame and associated with its residence time. The resulting values of $\eta_{\mathrm{CO}}$ for the sooting fuels are plotted as a function of residence time normalized by the smoke point residence time in Fig. 8 (nonsooting methanol and ethanol will be taken up later). As before, symbols only are identified by fuel type and burner diameter.

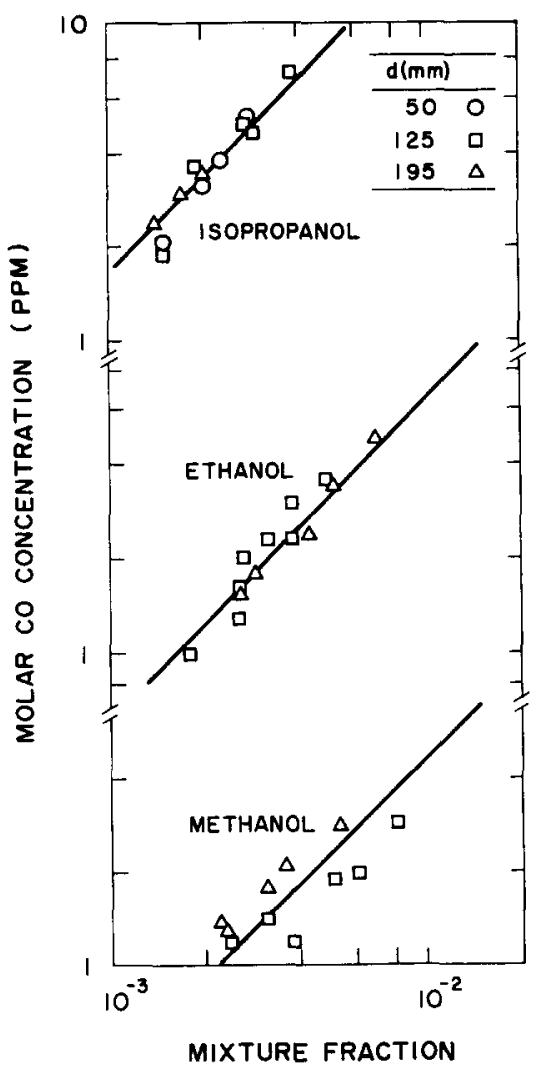

Fig. 7. Carbon monoxide state relationships for the overfire region of turbulent alcohol diffusion flames burning in air.

Similar to $\eta_{s}$ illustrated in Fig. 4 , the $\eta_{\mathrm{CO}}$ illustrated in Fig. 8 exhibit relatively little variation with residence time, typical of behavior in the long residence time regime. The similarity between the order of $\eta_{s}$ and $\eta_{\mathrm{CO}}$ with fuel type, and their behavior with respect to variations of residence time, is striking and suggests a close relationship between the processes responsible for soot and $\mathrm{CO}$ emissions from the present sooting flames, similar to earlier observations for gasfueled flames $[7,8]$.

Associating $\mathrm{CO}$ and soot emission, however, must be tempered by the observation that methanol and ethanol still emit $\mathrm{CO}$ even though they do not emit soot. As suggested by the correlation of measurements of $\mathrm{CO}$ concentrations for these flames illustrated Fig. 7, the $\eta_{\mathrm{CO}}$ for these flames were essentially independent of residence time over the present test range, which is typical of behavior in the long residence time regime, e.g., $\eta_{\mathrm{CO}}=0.0012$, with a standard deviation of 0.0004 for both methanol and ethanol. This value 


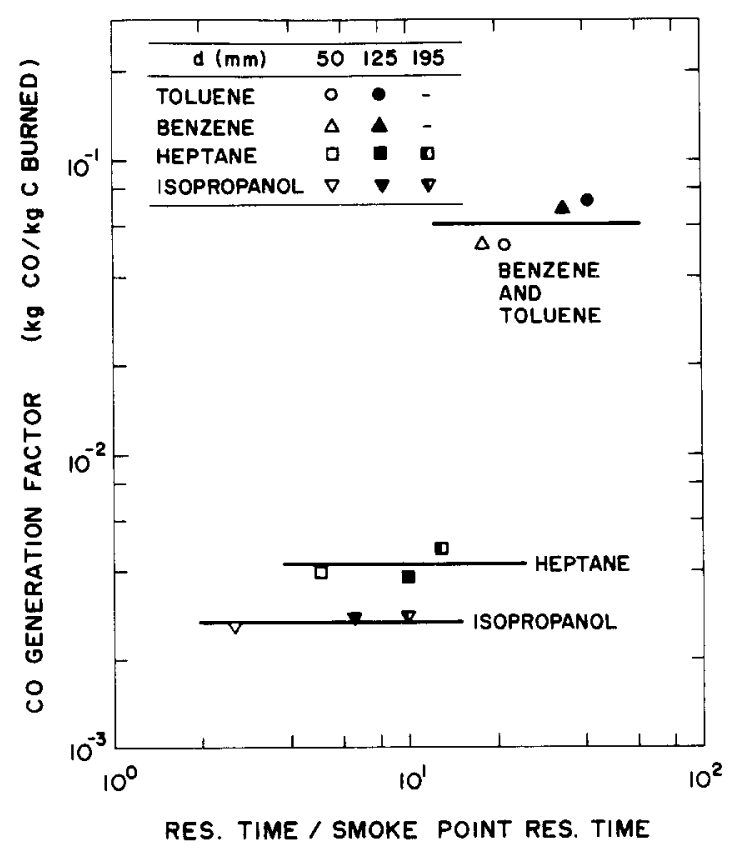

Fig. 8. Carbon monoxide generation factors as a function of residence time for turbulent toluene, benzene, $n$-heptane, and isopropanol diffusion flames burning in air.

is comparable to earlier observations for methane, which is also nonsooting, e.g., $\eta_{\mathrm{CO}}=0.0018$, with a standard deviation of 0.0003 [8]. Thus, $\mathrm{CO}$ generation factors for nonsooting fuels are significantly lower than for sooting fuels. This suggests that small emissions of $\mathrm{CO}$ that are not associated with soot may still contribute to $\mathrm{CO}$ emissions from sooting flames.

\section{Correlation of $\mathrm{CO}$ and Soot Emissions}

The correlation between $\mathrm{CO}$ and soot generation factors is illustrated in Fig. 9. Results shown in Fig. 9 include the present findings for liquidfueled flames, the earlier findings for gas-fueled flames $[7,8]$, and results from the extensive tabulation of Tewarson [2]. All the values of $\eta_{s}$ involve laser extinction measurements at 632.8 $\mathrm{nm}$, assuming the small particle (Rayleigh scattering) limit, which were reduced to soot volume fractions using the refractive indices of Dalzell and Sarofim [15] and then converted to $\eta_{s}$ using the soot density of Newman and Steciak [25]. Measurements from this laboratory are identified by burner size; as noted earlier, flame properties are not identified for the results of Tewarson [2], but these measurements presumably involved large flames in the long residence time regime. Finally, $\eta_{\mathrm{CO}}$ for the nonsooting methane, methanol, and ethanol flames are shown at the left of the plot, to suggest a baseline when $\eta_{s}$ is zero.

Except for methane and the alcohols, results illustrated in Fig. 9 exhibit a strong correlation between $\eta_{\mathrm{CO}}$ and $\eta_{s}$. The correlation of measurements from the present laboratory can be quantified reasonably well by the linear fit

$\eta_{\mathrm{CO}}=0.37 \eta_{s}$

over the range $0.008<\eta_{s}<0.2$, with standard deviation of the fit over this range of 0.09 . A similar fit was found during study of the gas fuel flames over the same range of $\eta_{s}[8], \eta_{\mathrm{CO}}=$ $0.34 \eta_{s}$, with a standard deviation of 0.09 . In view of the standard deviations of the two expressions, however, their differences are not statistically significant. For $\eta_{s}>0.008$, Eq. 10 implies that the mass of fuel carbon leaving the flames as $\mathrm{CO}$ and soot divides so that roughly $14 \%$ is associated with $\mathrm{CO}$.

Findings for the nonsooting fuels and for the relatively lightly sooting isopropanol indicate that there also is a mechanism for emission of $\mathrm{CO}$ from turbulent diffusion flames that is not associated with soot. This mechanism is responsible for all the $\mathrm{CO}$ emissions for nonsooting fuels, where averaging measurements from this laboratory for methane, methanol, and ethanol yields.

$\eta_{\mathrm{CO}}=0.0014$, nonsooting flames,

with a standard deviation of 0.0003 . Thus, for these fuels, Eq. 11 implies that roughly $0.06 \%$ of the mass of fuel carbon goes into the formation of $\mathrm{CO}$ by a nonsooting mechanism.

If the approximation is made that the nonsooting and sooting contributions of $\mathrm{CO}$ are simply additive, combining Eqs. 10 and 11 yields

$\eta_{\mathrm{CO}}=0.0014+0.37 \eta_{s}$,

with standard deviations at the limits of large and small $\eta_{s}$ being the same as before. The correlation of Eq. 12 is also illustrated in Fig. 9. It is seen that this relationship provides a reasonable fit of the measurements for weakly sooting isopropanol, e.g., the values of $\eta_{\mathrm{CO}}$ from the measurements and the correlation of Eq. 12 are 0.0027 and 0.0026 , respectively. The results tabulated by 

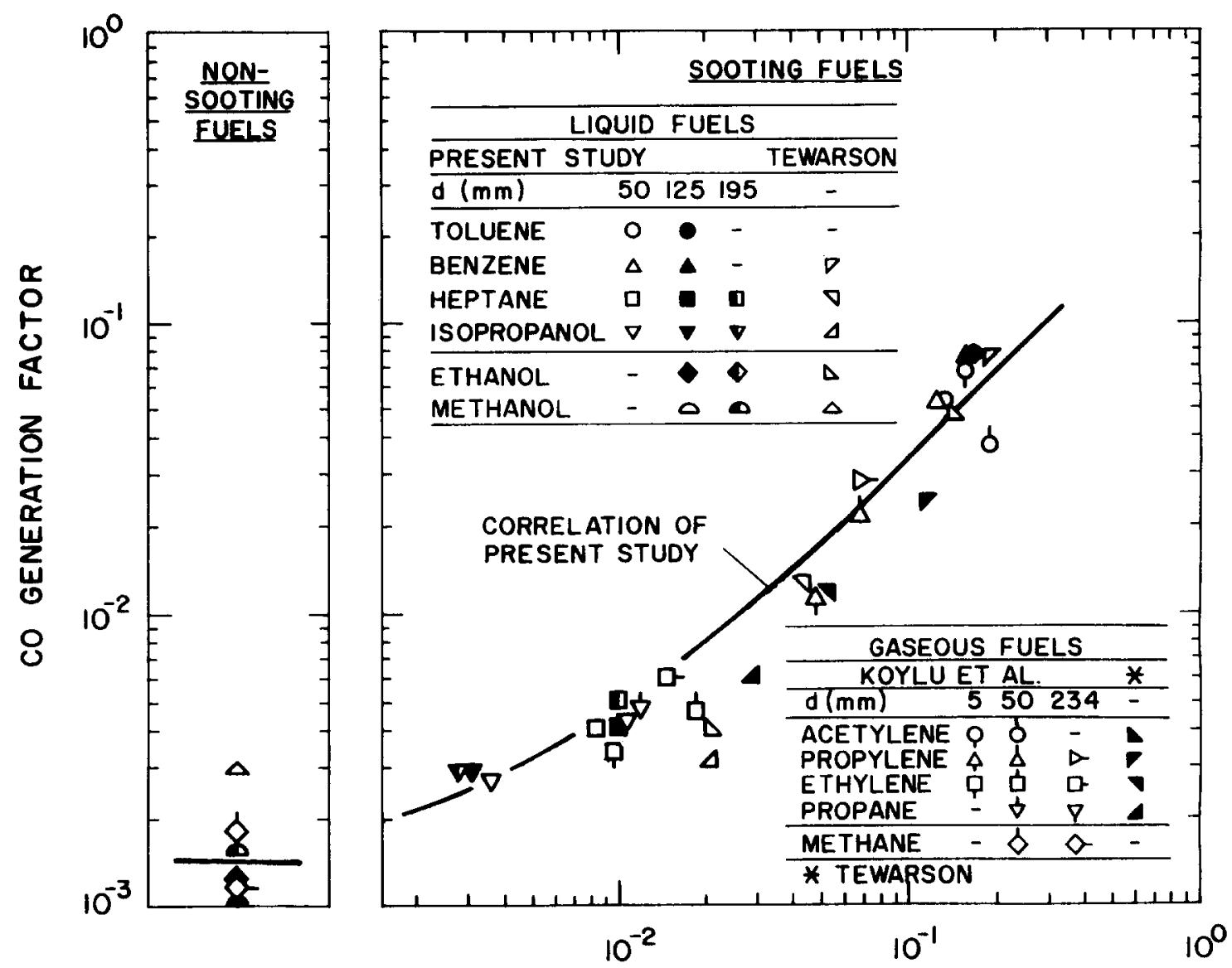

SOOT GENERATION FACTOR

Fig. 9. Carbon monoxide generation factors as a function of soot generation factors for various liquid- and gas-fueled turbulent diffusion flames burning in air. Other data from Tewarson [2] and Köylü et al. [8].

Tewarson [2] and illustrated in Fig. 4 are seen to be in reasonable agreement with Eq. 12 well.

Findings concerning $\mathrm{CO}$ and soot emissions of the liquid fuels in the long residence time regime are summarized in Table 3 . Entries include $\eta_{\mathrm{CO}}, \eta_{s}$, and their ratio, $\eta_{\mathrm{CO} / s}=\eta_{\mathrm{CO}} / \eta_{s}$ (for sooting fuels), which represents the mass of $\mathrm{CO}$ emitted per unit mass of soot emitted from the flame. Table 3 also includes values of these parameters from Tewarson [2]. Like Fig. 9, all $\eta_{s}$ values were based on extinction measurements using a soot density of $1100 \mathrm{~kg} / \mathrm{m}^{3}$, and involve flames in the long residence regime.

In general, the agreement between present results and those of Tewarson [2] for liquid fuels in Table 3 is much poorer than was observed for the gaseous fuels [8]. The largest discrepancies are for the alcohols, where Tewarson [2] generally indicates much larger emissions of $\mathrm{CO}$ and soot than the present study (particularly for methanol and ethanol where the present flames did not emit any soot at all). The reasons for these differences is not known. However, due to the importance of $\mathrm{CO}$ and soot emissions from buoyant turbulent flames, additional measurements to evaluate the properties of the liquid fuels given in Table 3, as well as for a broader range of fuels, is clearly merited.

In spite of some quantitative differences, present and earlier findings [8] suggest the presence of sooting and nonsooting mechanisms for the formation of $\mathrm{CO}$. The sooting mechanism appears to involve processes within the soot layer as it passes from fuel-rich to fuel-lean conditions. Certainly, the presence of $\mathrm{CO}$ in this layer as long as soot is present, even though CO and soot forma- 
TABLE 3

$\mathrm{CO}$ and Soot Generation Factors for Liquid Fuels ${ }^{a}$

\begin{tabular}{|c|c|c|c|c|c|c|}
\hline Fuel & Toluene & Benzene & $n$-Heptane & Isopropanol & Ethanol & Methanol \\
\hline \multicolumn{7}{|l|}{$\eta_{\mathrm{CO}}$} \\
\hline Present & 0.063 & 0.061 & 0.0042 & 0.0027 & 0.0012 & 0.0012 \\
\hline Tewarson [2] & - & 0.070 & 0.012 & 0.003 & 0.004 & 0.0030 \\
\hline \multicolumn{7}{|l|}{$\eta_{s}$} \\
\hline Present & 0.16 & 0.15 & 0.0095 & 0.0032 & 0.00 & 0.00 \\
\hline Tewarson [2] & - & 0.19 & 0.044 & 0.023 & 0.023 & $<0.003$ \\
\hline \multicolumn{7}{|l|}{$\eta_{\mathrm{CO} / \mathrm{s}}$} \\
\hline Present & 0.394 & 0.407 & 0.422 & 0.844 & - & - \\
\hline Tewarson [2] & - & 0.368 & 0.273 & 0.130 & 0.174 & $>1.00$ \\
\hline
\end{tabular}

${ }^{a}$ Present results for the long residence-time regime. All $\eta_{s}$ estimated from optical measurements using a soot density of 1100 $\mathrm{kg} / \mathrm{m}^{3}$.

tion mechanisms in the layer are certainly not the same, is reasonable based on past work: in the fuel-rich region, the soot layer (or soot spike) just on the fuel-rich side of stoichiometric involves maximum concentrations of both $\mathrm{CO}$ and soot in the flame [7, 13]; soot generally oxidizes to $\mathrm{CO}$ as a first step and $\mathrm{OH}$ plays a strong role in oxidizing both $\mathrm{CO}$ and soot $[1,6]$ so that the continued presence of soot implies the continued presence of $\mathrm{CO}$ as well; and radiative heat losses from soot implies lower temperatures as the soot layer passes from fuel-rich to fuel-lean conditions than at other points along the flame sheet, which should contribute to reduced rates of oxidation of $\mathrm{CO}$ and help to quench reactions before $\mathrm{CO}$ oxidation is complete. Recent measurements in the soot layer of laminar flames tend to support this general picture, suggesting that competition between $\mathrm{CO}$ and soot for the oxidizer species $\mathrm{OH}$ can be responsible for high $\mathrm{CO}$ emissions from sooting flames, with radiative quenching (to reduce $\mathrm{OH}$ ) possibly important in fuel-lean regions [6].

In In addition to emission of $\mathrm{CO}$ associated with the soot layer, however, conventional emission of $\mathrm{CO}$ from regions of the flame sheet not crossed by the soot layer is also expected. This involves quenching of $\mathrm{CO}$ oxidation reactions as temperatures drop when moving away from the flame sheet toward fuel-lean conditions, followed by passive mixing in the overfire region. This mechanism would explain the low level $\mathrm{CO}$ emissions from the nonsooting fuels but probably contributes to some extent to $\mathrm{CO}$ emissions from sooting fuels as well. Nevertheless, the sooting mechanism of $\mathrm{CO}$ emissions is generally domi- nant for sooting flames. This helps explain the limited success of past attempts to predict $\mathrm{CO}$ emissions from turbulent diffusion flames which ignore the presence of soot [27], although these methods still may be helpful for treating the nonsooting $\mathrm{CO}$ mechanism.

\section{CONCLUSIONS}

Soot and carbon monoxide emissions were studied for overventilated buoyant turbulent diffusion flames involving liquid fuels (toluene, benzene, $n$-heptane, isopropanol, ethanol, and methanol) burning in still air. The main conclusions of the study are as follows:

1. Similar to earlier findings for sooting gaseous fuels (acetylene, propylene, ethylene and propane), soot and $\mathrm{CO}$ generation factors were uniform throughout the overfire region for a given fuel and operating condition, implying both passive mixing in the overfire region and constant conditions when soot and $\mathrm{CO}$ oxidation reactions quench-independent of position in the flame.

2. Present measurements for sooting flames involved flame residence times generally an order of magnitude larger than the laminar smoke point residence time. Then, similar to the gas-fueled flames $[7,8]$, soot and $\mathrm{CO}$ generation factors were relatively independent of flame residence time in this long residence time regime.

3. Nonsooting methanol and ethanol flames exhibited lower levels of $\mathrm{CO}$ emissions than the sooting flames but their $\mathrm{CO}$ generation factors 
also were uniform over the overfire region and were relatively independent of residence time (for residence times greater than $245 \mathrm{~ms}$ ).

4. The correlations between $\mathrm{CO}$ and soot emissions could be represented as $\eta_{\mathrm{CO}}=0.0014$ $+0.37 \eta_{s}$ from measurements in this laboratory for both gas $[7,8]$ and liquid fuels. This suggests sooting and nonsooting mechanisms for $\mathrm{CO}$ emissions from flames, with the former dominating $\mathrm{CO}$ emissions from sooting flames. The sooting mechanism is associated with processes within the soot layer as it passes from fuel-rich to fuel-lean conditions; it is conjectured that the nonsooting mechanism involves quenching of $\mathrm{CO}$ oxidation reactions on the fuel-lean side of the flame sheet in regions where the soot layer does not cross the flame sheet.

5. Present measurements of $\mathrm{CO}$ and soot generation factors for the liquid fuels were in much poorer agreement with the tabulation of Tewarson [2] than was observed earlier for gaseous fuels $[7,8]$ (particularly for methanol and ethanol, which did not emit soot during present measurements but are listed as soot emitters in [2]). The reason for this behavior is not known. Additional measurements of soot and $\mathrm{CO}$ emissions from buoyant turbulent diffusion flames are needed to help resolve these discrepancies and to study the relationships between $\mathrm{CO}$ and soot emissions for a broader range of materials representative of the environment of unwanted fires.

This research was supported by the Center for Fire Research of the National Institute of Standards and Technology, Grant No. 60NANB8D033, with H. R. Baum serving as Scientific Officer.

\section{REFERENCES}

1. Friedman, R., Fire Safety Science: Proceedings of the First International Symposium, Hemisphere, Washington, 1986, p. 349.

2. Tewarson, A., in SFPE Handbook of Fire Protection Engineering, National Fire Protection Association, Quincy, MA, 1988, pp. 1-179.

3. Tewarson, A., and Newman, J. S., Fire Safety Science: Proceedings of the First International Symposium, Hemisphere, Washington, 1986, p. 451.

4. Fischer, S. J., and Grosshandler, W. L., Twenty-Sec- ond Symposium (International) on Combustion, The Combustion Institute, Pittsburgh, 1988, p. 1241.

5. McCaffrey, B. J., and Harkleroad, M., Twenty-Second Symposium (International) on Combustion, The Combustion Institute, Pittsburgh, 1988, p. 1251.

6. Puri, R., and Santoro, R. J., Fire Safety Science: Proceedings of the Third International Symposium, Hemisphere, Washington, in press.

7. Sivathanu, Y. R., and Faeth, G. M., Combust. Flame 81:133-149 (1990).

8. Köylü, Ü. Ö., Sivathanu, Y. R., and Faeth, G. M., Fire Safety Science: Proceedings of the Third International Symposium, Hemisphere, Washington, in press.

9. Bilger, R. W., Combust. Flame 30:277-284 (1977).

10. Sivathanu, Y. R., and Faeth, G. M., Combust. Flame 82:211-230 (1990).

11. Schug, K. P., Manheimer-Timnat, T., Yaccarino, P., and Glassman, I., Combust. Sci. Technol. 22:235-250 (1980).

12. Flower, W. L., and Bowman, C. T., Twenty-First Symposium (International) on Combustion, The Combustion Institute, Pitsburgh, 1986, p. 1115.

13. Gore, J. P., and Faeth, G. M., J. Heat Transf., 110:173-181 (1988).

14. Santoro, R. J., Dobbins, R. A., and Semerjian, H. G., Prog. Astronaut. Aeronaut. 92:343-382 (1984).

15. Dalzell, W. H., and Sarofim, H. F., J. Heat Transf. 91:100-104 (1969).

16. Gore, J. P., Ph.D. thesis, The Pennsylvania State University, University Park, PA, 1986.

17. Zukoski, E. E., Cetegen, B. M., and Kubota, T., Twentieth Symposium (International) on Combustion, The Combustion Institute, Pittsburgh, 1984, p. 361 .

18. Olson, D. B., Pickens, J. C., and Gill, R. J., Combust . Flame 62:43-60 (1985).

19. Clarke, A. E., Hunter, T. G., and Garner, F. H., Inst. Petrol. 32:627 (1946).

20. Steward, F. R., Combust. Sci. Technol. 2:203-212 (1970).

21. Thomas, P. H., Ninth Symposium (International) on Combustion, The Combustion Institute, Pittsburgh, 1962, p. 844.

22. You, H.-Z., and Faeth, G. M., Fire Materials 3:140- 147 (1979).

23. Drysdale, D., An Introduction to Fire Dynamics, Wiley, New York, 1985, p. 126.

24. Glassman, I., Twenty-Second Symposium (International) on Combustion, The Combustion Institute, Pittsburgh, 1988, p. 295.

25. Newman, J. S., and Steciak, J., Combust. Flame 67:55-64 (1987).

26. Markstein, G. H., Twentieth Symposium (International) on Combustion, The Combustion Institute, Pittsburgh, 1984, p. 1055.

27. Bilger, R. W., and Stårner, S. H., Combust. Flame 51:155- 176 (1983).

Received 29 March 1991; revised 26 June 1991 